\title{
UPOZNATOST SLAVONSKIH POLJOPRIVREDNIKA S MELIORATIVNIM ZAHVATIMA I NJIHOVOM UTJECAJU NA STABILNOST PRINOSA
}

\author{
HOW WELL SLAVONIAN FARMERS ARE ACQUAINTED WITH \\ THE MELIORATIVE SYSTEMS AND THEIR INFLUENCE ON THE \\ YIELD STABILITY
}

\section{R. Benković, Božica Japundžić-Palenkić, Teuta Benković Lačić}

\section{SAŽETAK}

Meliorativne mjere navodnjavanja i odvodnje suvišne vode spadaju u važnu strategiju razvoja održive poljoprivredne proizvodnje u regijama s nepovoljnim klimatskim uvjetima. Cilj ovoga rada bio je utvrditi koliko su slavonski poljoprivrednici educirani $\mathrm{i}$ upoznati $\mathrm{s}$ unaprjeđenjem poljoprivredne proizvodnje putem ulaganja u meliorativne sustave. Stoga je anketa o educiranosti slavonskih poljoprivrednika te njihovoj spremnosti na unaprjeđenje poljoprivredne proizvodnje, odnosno ulaganje u meliorativne sustave i stabilnost prinosa provedena u periodu od 17.10.2016. do 20.01.2017. godine $u$ pet slavonskih županija (Brodsko-posavskoj, Osječko-baranjskoj, Vukovarskosrijemskoj, Sisačko-moslavačkoj i Požeško-slavonskoj). Uzorak je činilo 30 ispitanika iz svake od pet slavonskih županija (ukupno 150) zaposlenih u poljoprivredi i drugim djelatnostima vezanim za poljoprivredu. Ispitanicima su postavljena dvadeset četiri pitanja koja su se odnosila na glavnu djelatnost njihova rada, stupanj obrazovanja, veličinu obrađivanih površina, održavanje meliorativnog sustava, način navodnjavanja i temeljna znanja o povećanju prinosa primjenom meliorativnih sustava. Istraživanjem je utvrđeno da najveći broj ispitanika obrađuje površine veličine 1-3 ha na kojima postoji problem suvišne vode i čije sustave odvodnje održavaju uglavnom vlasnici. Rezultati pokazuju da se u istraživanim županijama javlja problem nedostatka vode, a dominantni način navodnjavanja je prirodnim putem oborinskim vodama. Anketa ukazuje na svijest poljoprivrednih proizvođača da ulaganjem u meliorativne sustave odvodnje i navodnjavanja očekuju redovite prinose ali i povećanje prinosa.

Ključne riječi: poljoprivreda, melioracije, procjena, povećanje prinosa 
R. Benković i sur.: Upoznatost slavonskih poljoprivrednika s meliorativnim zahvatima i njihovom utjecaju na stabilnost prinosa

\begin{abstract}
Meliorative measures as irrigation and drainage are part of an important strategy for development of sustainable agricultural production in the regions with adverse climatic conditions. The aim of this paper was to determine how well Slavonian farmers are educated and acquainted with the improvement of agricultural production by investing in meliorative systems. This questioner survey on the education of Slavonian farmers and their willingness to improve agricultural production, investing in meliorative systems and yield stability, was carried out in the period from 17. October 2016. to 20. January 2017. in five Slavonian counties (Brod-Posavina, Osijek-Baranja, Vukovar-Srijem, SisakMoslavina and Požega-Slavonia). The sample consisted of 30 respondents from each of the five Slavonian counties (a total of 150 respondents) employed in agriculture and other activities related to agriculture. Respondents were asked twenty-four questions related to the main activity of their work, the level of education, the size of cultivated areas, the maintenance of the darinage system, the irrigation method, and basic knowledge about increasing the yield by applying meliorative systems. The survey found that most of the respondents cultivated areas of 1-3 ha with the problem of excess water and drainage systems which mostly maintained by the land owners. The results show that in the studied counties there is a problem of lack of water, and the dominant way of irrigation is by precipitation. The survey indicates the awareness of agricultural producers that they can expect constant and regular yields and even increase of yields by investing in meliorative systems.
\end{abstract}

Key words: agriculture, melioration, estimation, constant and regular yield

\title{
UVOD
}

Ljudska potreba za vodom i gospodarenje vodom ima vrlo veliku važnost $u$ održivosti kvalitete života na zemlji. Odatle dolazi potreba čovjeka za proširivanjem vlastitih stečenih i stručnih znanja za izgradnju i usavršavanje sustava za gospodarenje vodama. Zbog izrazitijih nestabilnih klimatskih prilika u posljednja dva desetljeća statistike bilježe sve veću ugroženost života kroz pomanjkanje pitke vode te djelomično ili potpuno uništenje poljoprivrednih nasada. Primjenom navodnjavanja kao melioracijske mjere možemo utjecati na neravnomjeran raspored oborina i dugotrajnih sušnih razdoblja koja umanjuju količinu i kvalitetu prinosa. 
R. Benković i sur.: Upoznatost slavonskih poljoprivrednika s meliorativnim zahvatima i njihovom utjecaju na stabilnost prinosa

Poljoprivreda kao jedna od karika lanca u proizvodnji hrane igra vrlo važnu ulogu u svakodnevnom životu. Osim kvalitetnog sadnog materijala, gnojidbe, obrade tla, zaštite, primjenjene agrotehnike posebnu pažnju potrebno je obratiti na lakodostupnu vlagu u tlu odnosno na odvodnju suvišne vode ili navodnjavanje u slučaju nedostatka vode.

Republika Hrvatska raspolaže značajnim vodnim gospodarstvom, a ima i cijeli niz propisa i planova iz područja zaštite voda.

Prema literaturnim izvorima izgrađenost sustava podzemne odvodnje i cijevne drenaže na poljoprivrednom zemljištu Republike Hrvatske kreće se od 134000 ha do 166000 ha (Petošić D. i sur. 2015.) Izvedenim hidromelioracijskim zahvatima u cilju povećanja poljoprivredne proizvodnje, uvelike je izmijenjena filtracijska sposobnost tih tala. Ograničene su mogućnosti sorpcije, povećana opasnost od onećišćenja tla, podzemnih voda i cijelog agroekosustava (Čoga L. i sur. 2003.).

Utjecaj navodnjavanja i cijene vode na profit $u$ mediteranskim španjolskim regijama proučavaju Fernández-Zamudio i sur. (2012.). Rezultati pokazuju da cijena vode značajno utječe na cijenu proizvedenog voća te se poljoprivrednog proizvođača potiče na proizvodnju profitabilnijih voćnih vrsta $\mathrm{s}$ manjim zahtjevima za vodom i ulazak u sustav održive upotrebe vode u poljoprivredi prema Europskoj direktivi o vodama (WFD). Ova direktiva predlaže cjelokupni povrat troškova za navodnjavanje dok onečišćavači podzemnih voda za to plaćaju posebne naknade.

Prihodi poljoprivrednog gospodarstva zbog cijene vode za navodnjavanje i izgradnje sustava mogu se smanjiti 25 - 40\% što može značajno otjecati na kvalitetu života poljoprivrednika (Berbela i Gomez-Limon, 2000.)

Utjecaj navodnjavanja na prinos uljne repice proučavali su davne 1978. godine (Clarke J. M. i Simpson G.M., 1978.) te su na osnovi dobivenih rezultata zaključili da svi istraživani sustavi navodnjavanja povećavaju broj mahuna po biljci i masu 1000 zrna.

Učinke navodnjavanja i lako dostupnog dušika na prinos krumpira proučavali su Ojala J.C. i sur., 1990. te su na osnovi dobivenih rezultata utvrdili da se prinos povećava u slučaju lako dostupnog dušika i kada nema navodnjavanja, ali je u konačnici najveći kada je navodnjavanje redovito a tlo sadržava dovoljno lako dostupnog dušika.

Kako podzemno navodnjavanje, navodnjavanje kapanjem i navodnjavanje brazdama utječe na prinos i kvalitetu šećerne repe proučavali su Hassanli 
R. Benković i sur.: Upoznatost slavonskih poljoprivrednika s meliorativnim zahvatima i njihovom utjecaju na stabilnost prinosa

i sur., 2010. Obradom rezultata istraživanja utvrdili su da je najveći prinos postignut metodom navodnjavnja kap po kap, a najveća koncentracija šećera u navodnjavanju brazdama.

Prinosa kukuruza u navodnjavanim uvjetima tijekom četiri godine pratili su Marković i sur., 2014. Analiza rezultata mjerenja električnih otpora ukazala je da se navodnjavanje može preporučiti kao učinkovita mjera osiguranja i povećanja prinosa unatoč vrlo promjenjivim klimatskim uvjetima.

Navodnjavanje je široko istraživana, vrijedna i održiva strategija poljoprivredne pro-izvodnje u regijama s nepovoljnim klimatskim uvjetima. Upotreba vode za navodnjavanje u različitim fazama rasta i osjetljivosti na sušu ima za cilj maksimizirati i stabilizirati produktivnost vode, a ne maksimalizirati prinose (Geerts i Raes, 2009.).

Pregledom odabranih istraživanja iz cijelog svijeta te sažimanjem prednosti i nedostaka navodnjavanja možemo potvrditi da je većina metoda navodnjavanja uspješna u povećanju produktivnosti vode, značajnom smanjenju stresa i osiguranju prinosa kulturnog bilja.

Cilj ovoga rada bio je utvrditi koliko su slavonski poljoprivrednici educirani $\mathrm{i}$ upoznati $\mathrm{s}$ unaprijeđenjem poljoprivredne proizvodnje putem ulaganja u meliorativne sustave.

\section{MATERIJAL I METODE}

Upitnik o educiranosti slavonskih poljoprivrednika te njihovoj spremnosti na ulaganje $u$ unaprjeđenje, odnosno osiguranje i stabilnost prinosa proveden je 2016/2017. godine u pet slavonskih županija (Brodsko-posavskoj, Osiječko-baranjskoj, Vukovarsko-srijemskoj, Sisačko-moslavačkoj i Požeškoslavonskoj). Uzorak je sastavljen od 30 ispitanika iz svake od pet slavonskih županija zaposlenih u poljoprivredi i drugim djelatnostima.

Pitanjima u anketnom upitniku prikupljeni su podaci o glavnoj djelatnosti ispitanika, stupnju obrazovanja, veličini obrađivanih površina, održavanju meliorativnog sustava, načinu navodnjavanja i općoj upoznatosti o povećanju prinosa primjenom meliorativnih sustava. $U$ radu su prikazani i obrađeni podaci s ukupno 150 obiteljska poljoprivredna gospodarstava iz 5 navedenih slavonskih županija. Za obradu anketom prikupljenih odgovora ispitanika i njihov grafički prikaz korišten je tablični kalkulator računalnog programa Microsoft Excell. 
R. Benković i sur.: Upoznatost slavonskih poljoprivrednika s meliorativnim zahvatima i njihovom utjecaju na stabilnost prinosa

\section{REZULTATI I RASPRAVA}

Socijalna struktura ispitanika

$\mathrm{Na}$ slici 1. prikazano je zvanje ispitanika ovisno o vezanosti za poljoprivredu u Brodsko-posavskoj, Osječko-baranjskoj, Požeško-slavonskoj, Sisačko-moslavačkoj i Vukovarsko-srijemskoj županiji.

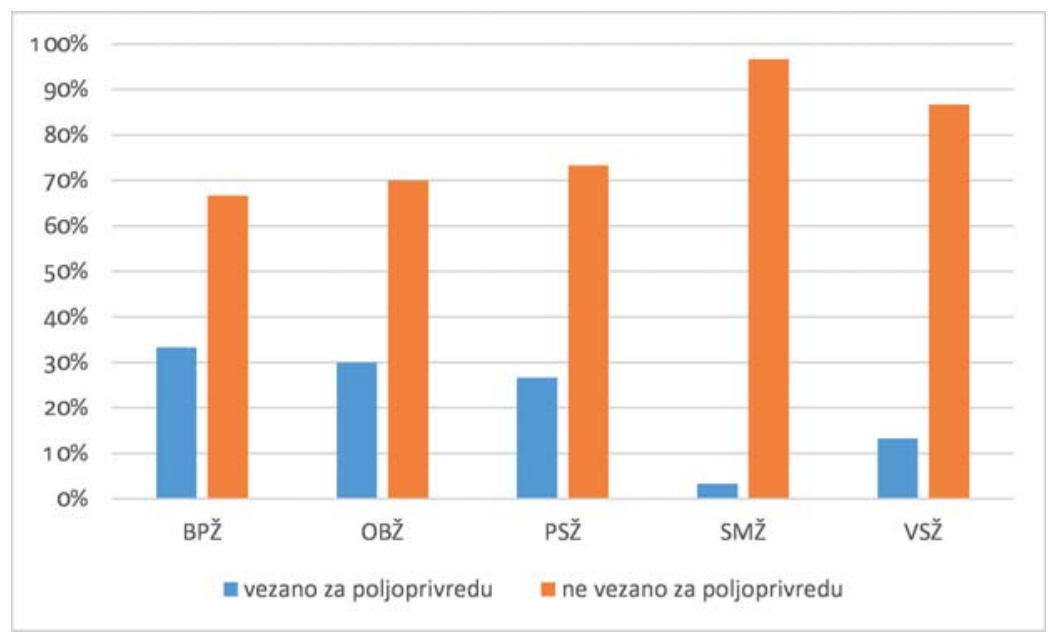

Slika 1. Zvanje ispitanika ovisno o vezanosti za poljoprivredu u Brodsko-posavskoj, Osječko-baranjskoj, Požeško-slavonskoj, Sisačko-moslavačkoj i Vukovarsko-srijemskoj županiji

Figure 1 Job of the respondent depending on the connection with agriculture in Brodsko-Posavska, Osječko-Baranjska, Požeško-Slavonska,

Sisačko-Moslavačka and Vukovarsko-Srijemska counti

Iz rezultata prikazanih u dijagramu na slici 1. , vidljivo je da u svim istraživanim županijama veći broj ispitanika ima zvanje koje nije vezano za poljoprivredu. U prosjeku, za sve županije, $79 \%$ ispitanika imalo je zvanje koje nije vezano za poljoprivredu, a $21 \%$ imalo je zvanje vezano za poljoprivredu. Najveća razlika između zvanja nevezanih za poljoprivredu i ,poljoprivrednih“ zvanja utvrđena je u Sisačko-moslavačkoj županiji (93\%), zatim Vukovarskosrijemskoj (73\%), Požeško-slavonskoj (47\%), Osječko-baranjskoj (40\%), a najmanja je u Brodsko-posavskoj županiji (33\%). Dodatnim istraživanjem utvrđeno je, prosječno za sve županije da većina ispitanika ima srednju stručnu spremu (71\%), a podjednaki je broj visokokvalificiranih i nekvalificiranih ispitanika (oko 10\%). 
R. Benković i sur.: Upoznatost slavonskih poljoprivrednika s meliorativnim zahvatima i njihovom utjecaju na stabilnost prinosa

Veličina proizvodne površine

Na slici 2. prikazana je veličina proizvodne površine koju koriste ispitanici $\mathrm{u}$ istraživanim slavonskim županijama.

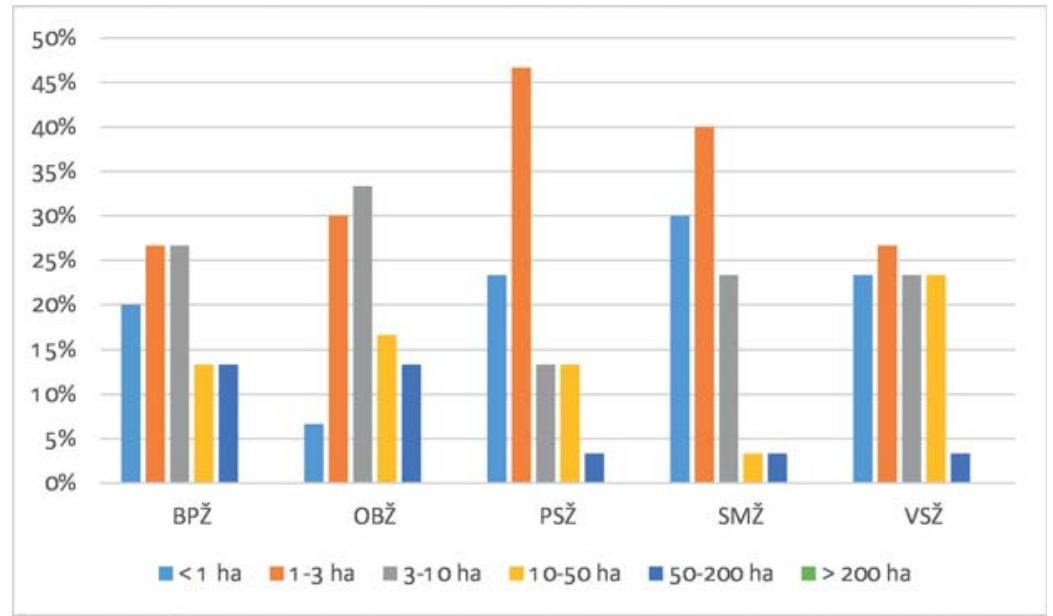

Slika 2. Veličina proizvodne površine koju koriste ispitanici $u$ istraživanim slavonskim županijama

Figure 2 The size of the production area used by the respondents in the invastegated Slavonian counties

Prema dobivenim podacima, u prosjeku za sve županije, najveći postotak proizvodnih površina (vlasništvo ili zakup) koje koriste ispitanici obuhvaćeni ovim istraživanjem pripada u kategoriju 1-3 ha (34\%). Proizvodne površine veličine 3-10 ha $\mathrm{i}$ manje od 1 ha zauzimaju $24 \%$ odnosno $21 \%$. Veće proizvodne površine (10-50 ha) zastupljene su sa $14 \%$, dok je upola manja zastupljenost proizvodnih površina veličine 50-200 ha. Ispitanici obuhvaćeni ovim istraživanjem ne koriste proizvodne površine veće od 200 ha. Na slici 2. vidi se da je najveća ujednačenost $u$ veličini proizvodnih površina utvrđena kod ispitanika u Brodsko-posavskoj županiji, zatim u Vukovarsko-srijemskoj i Osječko-baranjskoj županiji, a najmanja u Požeško-slavonskoj i Sisačkomoslavačkoj županiji.

Prema području poljoprivredne proizvodnje, za sve analizirane županije, ispitanici su se izjasnili da se najviše bave poljoprivrednom proizvodnjom iz više grana (41\%), zatim ratarstvom (19\%), povrćarstvom i/ili cvjećarstvom (15\%), voćarstvom ( $8 \%)$, vinogradarstvom (7\%), i stočarstvom ili nečim drugim (5\%). 
R. Benković i sur.: Upoznatost slavonskih poljoprivrednika s meliorativnim zahvatima i njihovom utjecaju na stabilnost prinosa

Prepoznavanje problema suvišne vode

$\mathrm{Na}$ postavljeno pitanje „Postoji li problem suvišne površinske i/ili podzemne vode na proizvodnim površinama?" ispitanici iz Osječko-baranjske županije većinom su odgovorili negativno dok su iz ostalih analiziranih županija ispitanici odgovorili potvrdno. Stoga je sljedeće pitanje bilo vezano za izvođenje radova i/ili održavanje postojećih sustava odvodnje u istraživanim slavonskim županijama. Rezultati tih istraživanja prikazani su na slici 3.

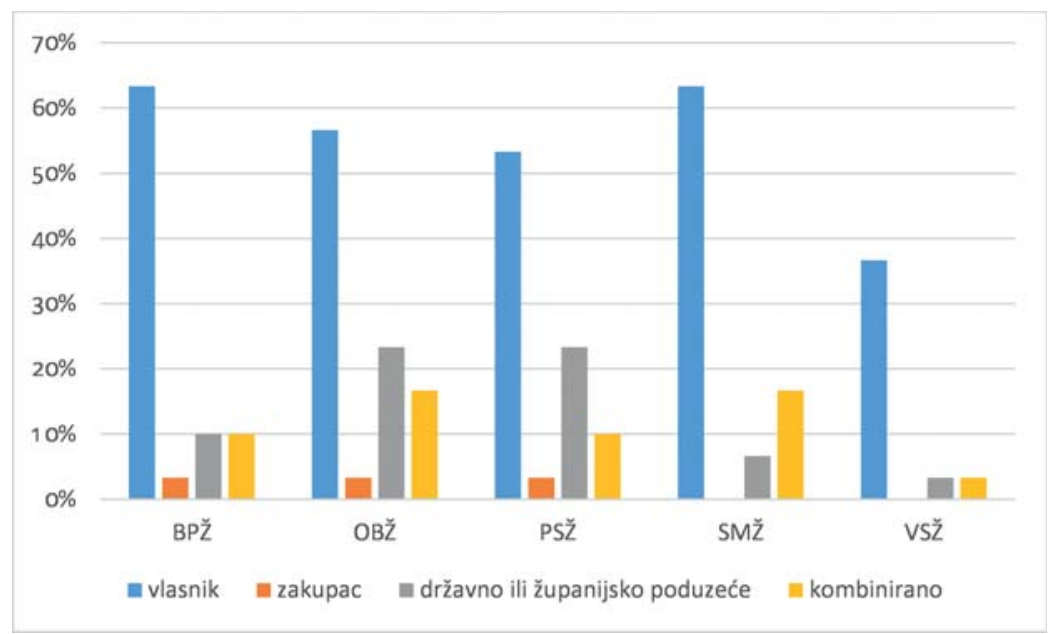

Slika 3. Prikaz održavanja sustava odvodnje po županijama

Figure 3 Drainage system maintenance per counties

U istraživanim županijama sustave odvodnje održavaju uglavnom vlasnici, prosječno $55 \%$. Županijska ili državna poduzeća prosječno održavaju $13 \%$ sustava odvodnje, a $11 \%$ sustava odvodnje održavaju kombinirano vlasnici, zakupci i županijska odnosno državna poduzeća. Najmanje, prosječno $2 \%$ sustava održavaju zakupci i to u Brodsko-posavskoj, Osječko-baranjskoj i Vukovarsko-srijemskoj županiji.

Prema odgovorima ispitanika o uključenosti u održavanje sustava odvodnje vidljivo je da se u Osječko-baranjskoj županiji održava $100 \%$ poljoprivredne proizvodne površine na neki od navedenih načina, nešto manje u Požeškoslavonskoj (90\%), jednako u Brodsko-posavskoj i Sisačko-moslavačkoj županiji (87\%), a najmanje (43\%) u Vukovarsko-srijemskoj županiji. 
R. Benković i sur.: Upoznatost slavonskih poljoprivrednika s meliorativnim zahvatima i njihovom utjecaju na stabilnost prinosa

Prepoznavanje problema nedostatka vode

Ispitanici u svim županijama potvrdno su odgovorili da postoji problem nedostatka vode. Najizraženiji nedostatak vode je na proizvodnim površinama kod ispitanika iz Požeško-slavonske i Osječko-baranjske županije. Putem ankete je istraženo na koji način proizvođači provode navodnjavanje, a rezultati su prikazani na slici 4 .

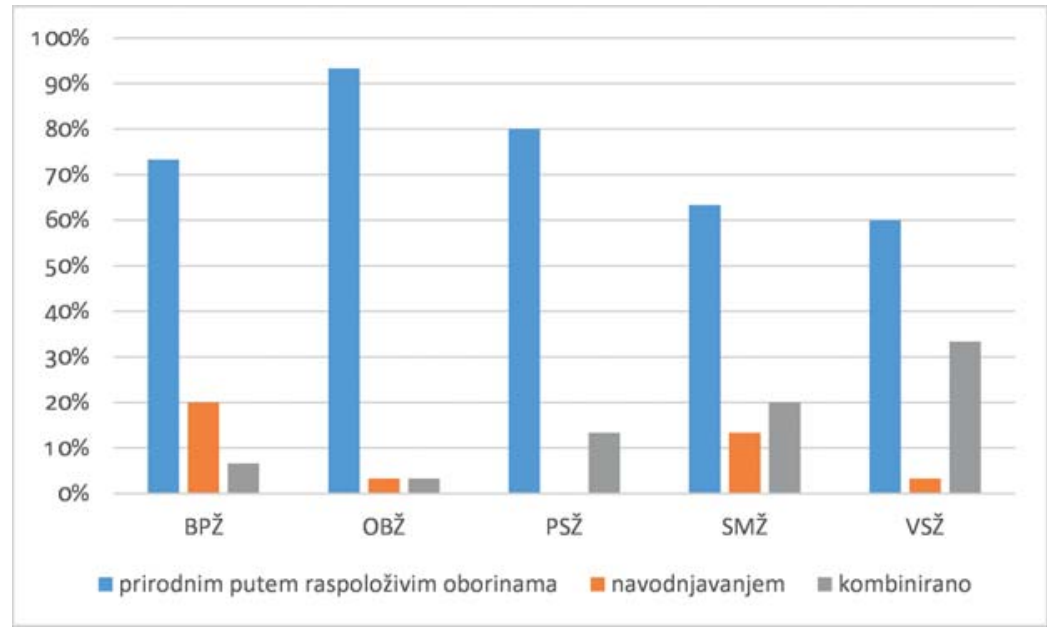

Slika 4. Načini navodnjavanja koje proizvođači provode

Figure 4 Irrigation models used

Kao što je vidljivo iz slike 4. u svim županijama dominantni način navodnjavanja je prirodnim putem raspoloživim oborinama. Najveća razlika između sustava navodnjavanja utvrđena je u Osječko-baranjskoj županiji. U toj županiji navodnjavanje proizvodnih površina sustavima navodnjavanja provodi se za manje od $90 \%$ u odnosu na navodnjavanje prirodnim putem raspoloživim oborinama i kombiniranim načinom. Proizvođači u Požeško-slavonskoj županiji koriste kombinirani sustav navodnjavanja na $13 \%$ površina što je za $67 \%$ manje od navodnjavanja prirodnim načinom. U Brodsko-posavskoj županiji za $46 \%$ više se navodnjava prirodnim putem $u$ odnosu na sustave navodnjavanja $i$ kombiniranim načinom, a u Vukovarsko-srijemskoj za 24\%.

Prirodni način navodnjavanja oborinama se provodi na $74 \%$ površina ispitanika svih pet slavonskih županija. Najmanje navodnjavanja (8\%) se provodi nekim od sustava navodnjavanja, a $15 \%$ navodnjavanja se provodi kombiniranjem oborina i nekog od sustava navodnjavanja. 
R. Benković i sur.: Upoznatost slavonskih poljoprivrednika s meliorativnim zahvatima i njihovom utjecaju na stabilnost prinosa

Poznavanje utjecaja melioracijskih mjera na prinos

Nakon dobivenih podataka o problemima suviška i nedostatka vode provedeno je ispitivanje vezano za to koliko meliorativne mjere utjeću na stabilnost odnosno moguće povećanje prinosa prema mišljenu poljoprivrednih proizvođača. Rezultati tih istraživanja prikazani su na slici 5.

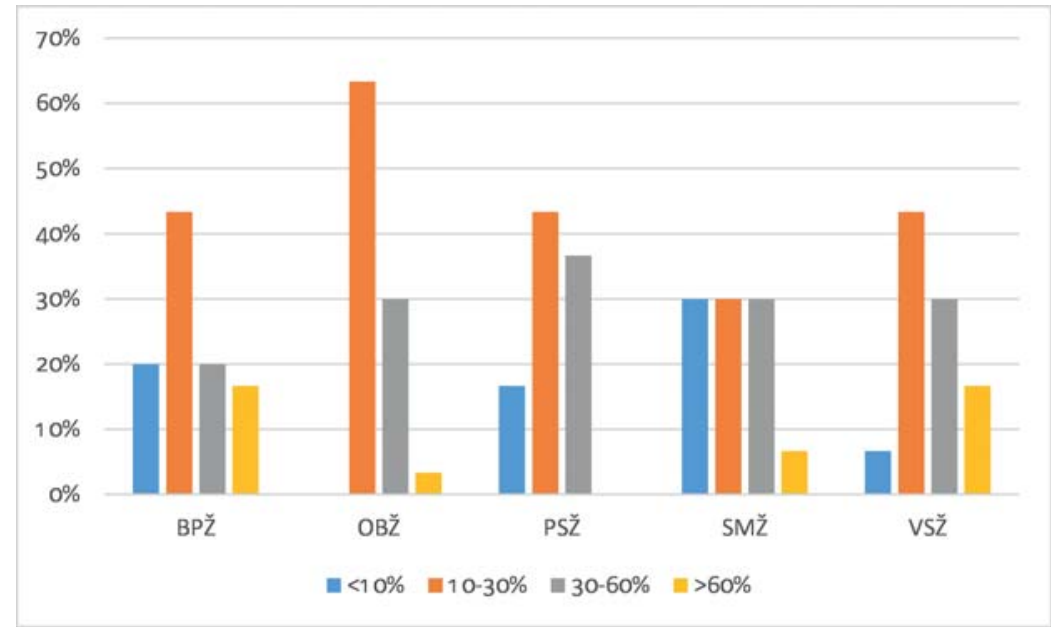

Slika 5. Procjena povećanja prinosa nakon provedenih meliorativnih mjera prema mišljenju proizvođača

Figure 5 Estimation of yield increase after implemented meliorative measures according to farmers

Proizvođači istraživanih županija smatraju da uključivanje meliorativnih mjera može povećati prinos na njihovim proizvodnim površinama. Najviše ispitanika (45\%) smatra da mogu podići prinos za 10-30\%. Manji broj proizvođača $(29 \%)$ misli da je povećanje prinosa moguće za 30-60\%. Povećanje prinosa manje od $10 \%$ očekuje $15 \%$ poljoprivrednih proizvođača. Najmanje proizvođača $(9 \%)$ misli da uključivanje meliorativnih mjera može podići prinos više od $60 \%$. 
R. Benković i sur.: Upoznatost slavonskih poljoprivrednika s meliorativnim zahvatima i njihovom utjecaju na stabilnost prinosa

\section{ZAKLJUCAK}

Nakon provedenog anketiranja 150 ispitanika u pet slavonskih županija uočljivo je da se poljoprivredom bavi najveći broj ispitanika koji nemaju zvanje i stručna znanja stečena u poljoprivrednoj djelatnosti (njih 79\%). Daljnom analizom je uočljiva mala proizvodna površina koja se koristi u poljoprivrednoj djelatnosti (najviši postotak veličine površine je od 1-3 ha), a poljoprivrednici se najviše bave nespecijaliziranom poljoprivrednom proizvodnjom (41\%). Iz ankete je vidljivo da su ispitanici svjesni svih problema koje im stvaraju klimatske neprilike odnosno prekomjerna vlažnost tlu i nedostatak vode. Sustave odvodnje održavaju uglavnom vlasnici proizvodnih površina $(55 \%)$ zbog slabog ili neredovitog održavanja od strane županijskih odnosno državnih poduzeća. Svi ispitanici smatraju korekcijske meliorativne mjere korisnima i upoznati su s mogućnostima povećanja prinosa uz njihovu primjenu. Unatoč nepredvidivim klimatski promjenama koje su u poljednjim desetljećima sve izraženije navodnjavanje nekim od mogućih sustava navodnjavanja koristi se na samo $8 \%$ proizvodnih poljoprivrednih površina. Većina ispitanika u provedenim istraživanju oslanja se na prirodne oborine (74\%). Iz dobivenih analiziranih podataka nameće se zaključak kako u poljoprivredoj proizvodnji ima puno prostora za širenje znanja, posebice o mogućnostima primjene meliorativnih mjera i sustava, te posljedično tome i napretku specijalizirane poljoprivredne proizvodnje.

\section{LITERATURA}

1. Berbela J., Gomez-Limon J.A. (2000.): The impact of water-pricing policy in Spain: an analysis of three irrigated areas, Agricultural Water Management 43 (2000) 219-238

2. Clarke J. M., Simpson G.M. (1978.): Influence of irrigation and seeding rates on yield and yield components of Brassica napus cv. Tower, Can. J. plant Sci.58: 731-737.

3. Čoga L., Ćustić M., Pecina M., Vršek I. (2003.): Utjecaj razmaka drenova na količinu ispranog dušika, Agriculturae Conspectus Scientificus, Vol. 68 (2003.) No. 1 (1-8)

4. Fernández-Zamudio M. A., Alcon F., De-Miguel M. D. (2012.): Effects of Irrigation-Water Pricing on the Profitability of Mediterranean Woody Crops, Problems, Perspectives and Challenges of agricultural Water Management, Dr. Manish Kumar (Ed.), ISBN: 978-953-51-0117-8, InTech 
R. Benković i sur.: Upoznatost slavonskih poljoprivrednika s meliorativnim zahvatima i njihovom utjecaju na stabilnost prinosa

5. Geerts S., Raes D. (2009.): Deficit irrigation as an on-farm strategy to maximize crop water productivity in dry areas, Agricultural Water Management Volume 96, Issue 9, September 2009, Pages 1275-1284

6. Hassanli A.M., Ahmadirad S., Beecham S. (2010.): Evaluation of the influence of irrigation methods and water quality on sugar beet yield and water use efficiency, Agricultural Water Management Volume 97, Issue 2, February 2010, Pages 357-362

7. Marković M., Šoštarić J., Josipović M., Petošić D., Šimunić I., Zebec V. (2014.): Implementation of irrigation scheduling based on monitoring of soil moisture content in extreme weather conditions, 6th International Scientific and Expert Conference TEAM 2014, Kecskemét, November 10-11, 2014.: 34-38

8. Ojala J. C., Stark J. C., Kleinkopf G. E. (1990.): Influence of irrigation and nitrogen management on potato yield and quality, American Potato Journal 1990., Vol.67 No.1 pp. 29-43 ref. 43

9. Petošić D., Husnjak S., Mustać I., Bakić H., Filipović V. (2015.): Inventarizacija sustava podzemne odvodnje na poljoprivrednim površinama u Republici Hrvatskoj, ocjena stanja i preporuke za obnovu i održavanje studija, Crored - Hrvatski registar drenaže, Zagreb 2015.

10. Škorić A., Filipovski G., Ciric M. (1985.): Land Classification of Yugoslavia, ANU BiH, knjiga 13, Sarajevo

Adrese autora - Author's addresses:

Robert Benković mag.ing.agr, e-mail: Robert.Benkovic@vusb.hr

Dr. sc. Božica Japundžić-Palenkić,

Dr. sc.Teuta Benković Lačić

Veleučilište u Slavonskom Brudu

Dr. Mile Budaka 1, Slavonski Brod
Primljeno - Received:

28.06.2018 
R. Benković i sur.: Upoznatost slavonskih poljoprivrednika s meliorativnim zahvatima i njihovom utjecaju na stabilnost prinosa 